\title{
Brief Discussion on Students' Creative Thinking Ability Cultivation in the "Fundamentals of Engineering Materials and the Machinery Manufacturing" Teaching Class
}

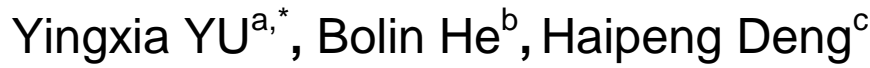 \\ School of Mechanical \& Electrical Engineering, East China Jiaotong University, Nanchang, Jiangxi, \\ 330013, China \\ ayyxhbl@136.com, bhebolin@163.com, ${ }^{\mathrm{c}} 1227871078 @ q q . c o m$
}

Keywords: Mechanical engineering materials; Machinery manufacturing base; Creative thinking ability; Teaching

\begin{abstract}
The aim of this article is to show how to enhance students' creative thinking ability. After trying, the result indicated that learning enthusiasm and creative thinking ability could be improved by teachers' guidance leading, consolidating difficult and important points and after class target experimental operation.

"Fundamentals of mechanical engineering materials and manufacturing" has become one of most important professional basic courses of mechanical specialties. The closely linked content with strong applicability demands students to grasp fundamental knowledge and then to choose right materials for components. It is most suitable for students to cultivate creative thinking ability.

Creative thinking absolutely a new kind of thinking mode emphasize on independency and creativity. Innovative thinking which not come out of blue is the fruits of long time accumulation under objective conditions. Tridimensional creative thinking is a kind of ideology based on the universal relation in things. Innovative thinking formed little by little possesses the quality of ductility and divergent. And it is the source for man to make great breakthrough in certain field. It is not unique to the minority, but for all of us. Following the natural law of thinking, innovative thinking is shaped by exploration and cultivation. Moreover, it focuses on the application in practice [1-5]. Though students learn mainly in reappearance thinking during school days, developing creative thinking has an indispensable status.

Aiming at the present problems of colleges of engineering materials and machinery manufacturing base in the course teaching, to stimulate students' interest in learning this course, recognizing the materials, processing technology, modern manufacturing technology in the production and life of modern industry and even the national defense construction in an important position, concrete measures were put forward as following.
\end{abstract}

\section{The implementation of effective teaching measures}

Students' interest in learning should be stimulated in the first lesson. Einstein once said: "interest is the best teacher". Learning interest in the classroom plays a huge role in learning effect improving, intelligence development, innovation ability training and teaching quality enhancement. Students in mechanical first get in touch with this course, so teachers must stimulate students' learning interest in the first class. History was taken as main line in teaching from the original stone-age, the bronze-age, the iron-age to the present age.

Learning of this class exerts a subtle influence on students' character. This course requires students to learn not only in class but also after class. So, teachers should provide effective learning methods for students and guide them. For example, learning interest could be cultivated by arranging two or more after-class exercises which is targeted and flexible. At the same time, do not let students lose confidence for the no-thinking answers. Furthermore, teachers request students briefly answer for 
questions using their own words. Many chapters are appropriate for students to learn by themselves. In those chapters, teachers can check learning effect by asking questions, analysis and summary. It saves a lot of teaching time. Learning interest and confidence would be built by enhancing learning ability in this way.

We must establish the main line of this course during learning the first chapter. This course control and change the properties of material on the basis of "Process-Structure-Performance", namely process determining structure, structure determining performance. Here, structure refers to "composition, structure"; process refers to material preparing and processing. The property change during using process also should be considered.

When choosing material for components, the teachers need to lead students to think problems in different ways. For example, the spring steel material whose elasticity, rigidity and fatigue strength are main requirements change its properties by selecting different composition (carbon content in alloy) and different processing (such as cold, thermoplastic processing, heat treatment, shot peening on surface). It appears that we should take not only composition but also processing into consideration to improve the properties of spring steel material.

Students may feel boring when they first learn materials properties and machining process. When teaching this content, teachers can mention the application of the properties and processing, motivating students, interest and enthusiasm. Material process is to meet the demand of most economical products. Comprehensive understanding of performance and its change rule of materials is an important basis for the design, material selection and application, making the process and quality inspection [6]. The mechanical engineering material lays a good theoretical foundation for machinery manufacturing.

\section{In-depth study of important and difficult points}

Learning process should be a process of thinking and learning alternating [7]. The thinking people are most commonly used in the process of learning is "reflective thinking", namely doubt -- find the problem -- collect materials -- logical reasoning -- to solve the problem. So we should often let students be interested in the real situation in teaching and let the student have the question or set, then contact the previous knowledge or to find the appropriate data to find solutions to problems, to enable students to actively think, blindly accepting the knowledge of dynamic thinking, cultivating students' logical thinking ability[8].

Multimedia technology and the traditional "blackboard + chalk" combined teaching method make the teaching quality and efficiency has been improved obviously in finite time, which deepened students' understanding of the teaching contents and improved the students' interest in learning[5]. For example, the crystal structure of a metal is more abstract. Students are difficult to understand. Through the multimedia technology, students are relaxed and happy to learn this knowledge by designing a series of animation, explain the abstract of the crystal structure step by step with the most common points. In this way, teachers help students to make transition from image thinking to abstract thinking.

The phase diagram is an important tool for material research, expressing the relationship between material composition, temperature, pressure and state. Iron carbon phase diagram which is the foundation of other phase diagram is so vital. It is an important, difficulty point in teaching. The content of it involves many new terms. It is difficult for students to grasp and understand. So we must pay attention to methods and techniques, to spend a few extra classes to make students understand. Firstly, teachers guided students to understand the characteristics of peritectic, eutectic and eutectoid reaction. Then the characteristics of the phase diagram were detailed analysed, to let the students understand the initial phase diagram. So, students can know the meaning and the name of each line and can draw iron carbon phase diagram by their own. Each class should be in the form of questions to help students repeated memory $A_{1}, A_{1}, A_{1}, A_{3}, A_{3}, A_{3}, A_{c m}, A c_{c m}, A_{c m}$ lines and other bits and pieces of knowledge. Finally, we must learn to use the lever principle to calculate the phase composition content 
and tissue composition content. After completely understanding of these concepts, students are easy to understand other phase diagrams.

The concepts for the next class should be given to students, so that students will search information to solve the problems. After Repeated consolidation, students could not only solve the doubt in heart, but also could make the engineering materials on this course as a whole. As result, all those things cultured actively thinking habits of the students, exercising their logic, which achieved very good teaching effect.

\section{Deepen the understanding of theoretical knowledge through the experiment}

This professional foundation course is closely related with practice [9]. If the abstract theory is explained directly, students feel more boring and difficult to understand. The experiment becomes lively and interesting, if students do it by themselves. The experiment is generally in the foundation of understanding, learned knowledge and flexibility [10]. Students must be combined with a large number of practical experiences to understand the textbook knowledge, especially the cold and hot processing part. Many steps and principle of speaking sounds very confusing, but as long as having a look in the shop or the site, it is not difficult to understand, even very simple and intuitive, such as composition of arc and microstructure and properties of welding joint.

After learning much theory, experiment can be arranged, including heat treatment, grinding metallographic, observation of microstructure, hardness test. Experiment arrangements enable students to obtain manipulative ability. Students will have more intuitive understanding of the properties of heat treatment materials, making a solid foundation for pre heat treatment in the future.

The concept that organization influences performance is permeated with the whole course. What is the organization? The organization which can't be seen by our eyes directly can be obtained by metallographic. Metallographic experiment allows students to learn how to do the sample, observe and understand the ferrite, cementite, and pearlite. This can be further deepened the understanding of phase diagram. So it will receive good result.

\section{Summary after learning}

The knowledge of this course is very complicated, but the regularity is also very strong. Summary after completing their studies is needed [6]. For example, when learning grades of steel, we can take "typical grades, main uses, performance requirements, the characteristic of chemical composition, heat treatment process and the corresponding organization" as the main line. The dispersed and complicated content will be highly concentrated and highly generalized. Other chapters also should be summarized in this way.

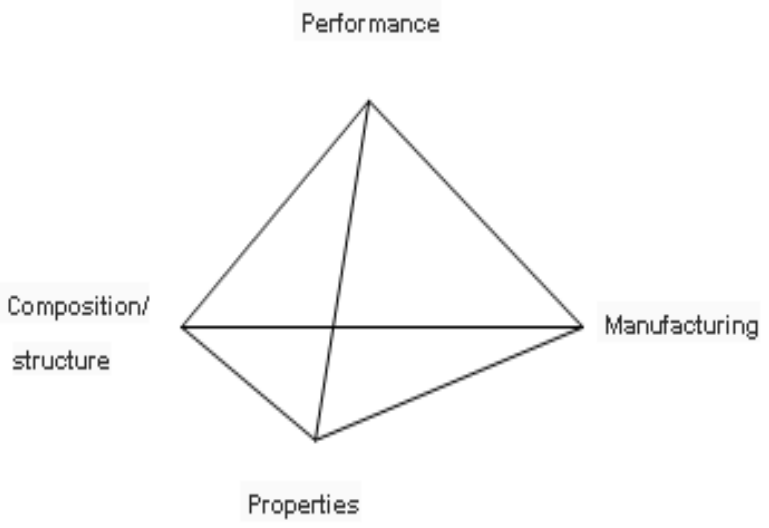

Figure. 1 Relationship between the contents 
Manufacturing technology change rapidly, new materials and new technology emerge constantly in the field of industrial, which make the teaching content more rich. It is imperative to deepen curriculum reform in teaching contents because of the fierce conflict between new and traditional teaching ideas, rich teaching contents and dwindling hours. Traditional teaching contents including the composition of material, matrials manufacturing, material properties and performane is shown in Figure 1.

"The chemistry composition + heat treatment, organization structure, performance and application" is the vertical line of this course. This vertical outline will help students combine all chapters as a whole.

\section{Acknowledgment}

The research is supported by the pilot project of professional comprehensive reform of general undergraduate colleges and universities in Jiangxi province (No.2013GZC0028), High-quality goods resource sharing class in Jiangxi province (No.[2012]130) and Fine course construction project in Jiangxi province (No.[2011]74).

\section{References}

[1] Lv Hong, Liu Rong. How to cultivate students' creative thinking ability of university English teaching[J]. Journal of Changchun University of Science and Technology, 2011, 6 (11): 100 - 101

[2] Wang Qinruo, Zhang Yun, Chen Wei, et al. Construction of National Characteristic Specialty for Automation Specialty[J]. Journal of Guangdong University of Technology(Social Sciences Edition), 2008, (8) S1: 192-193.(in Chinese)

[3] Guo Tiantai, Li Dongsheng, Xie Dailiang, et al. Extraction and Construction of a State-level Feature Specialty-Measurement \& Cont rol Technology and Instrumentation[J]. High Education of Chemical Industry. 2008, 12(6):7-10. (in Chinese)

[4] Li Yuanyuan. Enhance the Construction of Characteristic Specialty and Increase the Quality of personnel training[J]. China Higher Education, 2008, 17 (1):25-27. (in Chinese)

[5] Mao Guo bing, Zhang Guangsheng, Liu Qi. Reform and exploration for links of experimental teaching of material shaping and control engineering specialty[J]. Experimental Technology and Management,2010, 21(6):140-142. (in Chinese)

[6] Zhang Xiaoyan. Teaching reform and practice of "mechanical manufacturing basis" course [J]. Technology and market, 2011, 7(18): 529 - 531

[7] Ma Shibang, Zhang Hongfeng. Exploration and practice of teaching reform of the course of mechanical engineering materials [J]. GUANGXI JOURNAL OF LIGHT INDUSTRY, 2009,11(132): 168 - 169

[8] Wang Dongfeng. Developing students' thinking ability in "mechanical engineering materials" course teaching[J]. Education, 2009 (1): 93

[9] Zhang Youqiang, Luo Sshuli, Zhou Ling. To explore the course of mechanical engineering materials teaching[J]. China Modern Education Equipment, 2013, 3(163): 56 - 58

[10]Dong Binbin. The application of task driven method in the teaching of mechanical manufacturing basis [J]. GUANGXI JOURNAL OF LIGHT INDUSTRY, 2011, 7(152): 150 - 151 